\title{
Paediatrics in Barcelona
}

\author{
Fabio Midulla', Enrico Lombardi², Bart Rottier ${ }^{3}$, Anders Lindblad ${ }^{4}$, \\ Jonathan Grigg ${ }^{5}$, Kajsa Bohlin ${ }^{6}$, Franca Rusconi ${ }^{7}$, Petr Pohunek ${ }^{8}$ and Ernst Eber ${ }^{9}$
}

\section{Affiliations:}

'Dept of Paediatrics, Sapienza University of Rome, Rome, Italy.

2Dept of Paediatrics, Anna Meyer Children's University Hospital, Florence, Italy.

${ }^{3}$ Dept of Pediatric Pulmonology and Allergology, GRIAC Research Institute, Beatrix Children's Hospital, University of Groningen, Groningen, The Netherlands.

${ }^{4}$ Dept of Paediatrics, Queen Silvia Children's Hospital, Sahlgrenska University Hospital, Gothenburg, Sweden. ${ }^{5}$ Blizard Institute, Queen Mary University London, London, UK.

${ }^{6}$ Dept of Neonatology, Karolinska University Hospital and Karolinska Institutet, Stockholm, Sweden.

${ }^{7}$ Unit of Epidemiology, Anna Meyer Children's University Hospital, Florence, Italy.

${ }^{8}$ Dept of Paediatrics, 2nd Faculty of Medicine and University Hospital Motol, Charles University, Prague, Czech Republic.

${ }^{9}$ Respiratory and Allergic Disease Division, Dept of Paediatrics, Medical University of Graz, Graz, Austria.

Correspondence: Ernst Eber, Klinische Abteilung für Pulmonologie und Allergologie, Univ.-Klinik für Kinder- und Jugendheilkunde, Medizinische Universität Graz, Auenbruggerplatz 34/2, 8036 Graz, Austria. E-mail: ernst.eberdmedunigraz.at

ABSTRACT This update will describe the paediatric highlights from the 2013 European Respiratory Society (ERS) annual congress in Barcelona, Spain. Abstracts from the seven groups of the ERS Paediatric Assembly (Respiratory Physiology and Sleep, Asthma and Allergy, Cystic Fibrosis, Respiratory Infection and Immunology, Neonatology and Paediatric Intensive Care, Respiratory Epidemiology, and Bronchology) have been chosen by group officers and are presented in the context of current literature. 


\section{Introduction}

During the 2013 annual congress of the European Respiratory Society (ERS) in Barcelona, Spain, many high-quality scientific communications were presented by members of the Paediatric Assembly. As in the Scientific Assembly Update from the 2012 annual congress [1], officers of the scientific groups of the Paediatric Assembly have selected and discussed the most important abstracts from each group to provide readers with a review of the research that was presented during the meeting. It is not possible for this update to be comprehensive as there was such a large number of contributions at the congress; instead, the update aims to address the major areas of research in paediatric respiratory medicine.

\section{Paediatric respiratory physiology and sleep \\ Forced oscillations}

The forced oscillation technique (FOT) allows the measurement of respiratory impedance during tidal breathing and is particularly suitable in young children. Several researchers are currently focusing on applying this technique in clinical practice.

$100 \%$ feasibility of the inhaled mannitol airway challenge test using respiratory system resistance at $8 \mathrm{~Hz}$ $\left(R_{\mathrm{rs}_{8}}\right)$ has recently been shown in 17 children aged 4-7 years, whereas three 3-year-old children failed to complete the test owing to difficulty in sustaining attention [2].

AlbloOShi et al. [3] assessed the agreement between inhaled mannitol airway challenge (using a 50\% increase in $\mathrm{Rrs}_{8}$ as the outcome) and free running exercise challenge in 28 children aged 4-7 years. The two challenge tests yielded $65 \%$ concordance in 20 children with a history of exercise-induced respiratory symptoms, and $100 \%$ in eight healthy children, suggesting that a mannitol challenge test combined with FOT may help diagnose exercise-induced asthma in young children.

GAULD et al. [4] used FOT in 12 young children with spinal muscular atrophy (mean age 6.3 years). Rrs $s_{8}$ and respiratory system reactance at $8 \mathrm{~Hz}\left(\mathrm{Xrs}_{8}\right)$ were significantly abnormal and, in the four children who also underwent spirometry, a linear relationship was found between $X_{r s_{8}}$ and forced vital capacity $\left(R^{2}=0.54\right)$, assisted peak cough flow $\left(R^{2}=0.43\right)$ and unassisted peak cough flow $\left(R^{2}=0.33\right)$. When the investigators repeated the measurements 3-monthly over 12 months, the $X_{r_{8}}$ Z-score tended to improve ( +0.44 per annum), whereas the Rrss z-score worsened (+0.23 per annum). GAULD et al. [4] concluded that more research is needed to establish the value of FOT in managing individuals with spinal muscular atrophy.

RADICS et al. [5] assessed the changes in respiratory impedance during deep inspiration using the wave tube FOT in 42 unsedated healthy term newborns. Variables were measured during natural sleep within $24 \mathrm{~h}$ of birth. During a natural sigh, elastance increased with the increase in volume, whereas airway resistance decreased, reaching a minimum before the inspiratory volume peaked, which suggests that active mechanisms are involved. These data show that impedance can be measured during deep inspiration in unsedated newborns on their first day of life.

\section{Multiple-breath washout}

Several studies have reported multiple-breath washout (MBW) to be a feasible and potentially useful technique for research and clinical application in young children with cystic fibrosis (CF) [6]; indeed, a technical consensus statement on this technique has recently been published [7]. Several researchers are currently considering this technique from a technical viewpoint in young children and extending its implementation in the clinical setting to diseases other than CF.

Among others, SCHMidT et al. [8] evaluated, using a new lung model, the in vitro accuracy of two commercially available MBW setups, one using sulfur hexafluoride (SF6) for infants and one using helium for preschool children. The preschool MBW setup was also validated in vivo versus plethysmography in 20 preschool children. In vitro comparison showed only slight differences in the measured functional residual capacity (FRC) both in the infant model (mean relative difference $1 \%$ in the FRC range $80-300 \mathrm{~mL}$ ) and in the preschool model (relative difference up to $13 \%$ in the $400 \mathrm{~mL}$ FRC setting, $-2 \%$ in the FRC range 600-1400 mL), whereas in vivo FRC measured by plethysmography exceeded FRC measured by $\mathrm{MBW}$ by $38 \%$ (1081 versus $676 \mathrm{~mL}$ ), perhaps owing to physiological variability and differences in measurement techniques.

To improve its feasibility in paediatric clinical settings, STANOJEVIC et al. [9] measured nitrogen MBW in 42 healthy children and 37 children with CF. They found that the average lung clearance index (LCI) from several MBW trials overestimated the best LCI (from the first acceptable trial, with a breathing pattern most closely reflecting quiet tidal breathing) in $70 \%$ of children, suggesting that reporting the LCI from the best trial may minimise testing time and improve accuracy. 
To find out more about LCI diagnostic sensitivity in asthma, HATZIAGOROU et al. [10] assessed ventilation inhomogeneity in 18 children with well-controlled severe asthma and normal spirometry compared with 18 healthy age-matched controls. LCI was significantly higher in children with asthma than in controls, suggesting that LCI is more sensitive than spirometry in detecting lung function abnormalities in children with well-controlled severe asthma.

In a similar study, FuCHS et al. [11] assessed LCI using nitrogen MBW in 89 patients aged 4-73 years who had PiZZ $\alpha_{1}$-antitrypsin deficiency compared with 40 controls aged 7-84 years. Mean LCI was significantly higher in patients than in controls $(9.0$ versus 6.5$)$, showing ventilation inhomogeneity in patients. When compared with spirometry, LCI gave concordant results in $71 \%$ of patients ( 31 with abnormal LCI and abnormal spirometry, and 32 with normal LCI and normal spirometry), but 25 (28\%) patients had abnormal LCI and normal spirometry, confirming that LCI is more sensitive than spirometry for monitoring $\alpha_{1}$-antitrypsin deficiency-related lung disease.

Finally, YAMMINE et al. [12] studied ventilation inhomogeneity at school age (mean age 10.1 years) in 34 children born preterm (mean gestational age 28.6 weeks) and 27 term-born controls using nitrogen MBW, nitrogen single-breath washout (SBW) and helium/SF6 mixture SBW at school age. Although no significant difference was found in LCI between children born preterm and controls, ventilation inhomogeneity in the conductive airway zone (Scond) and the phase III (SIII) slope was higher in children born preterm than in controls, suggesting that ventilation inhomogeneity in the lung periphery is more affected than global ventilation inhomogeneity in former preterm children at school age.

\section{Reference values}

Several groups have focused on determining appropriate reference values for various tests.

GAULD et al. [13] found that the existing reference equation for height prediction from ulna length [14] in older children overestimated height in 234 2-6 year-old-children and provided appropriate reference equations for estimating height in children with mobility or joint problems in this age range.

Conversely, focusing on spirometry, HüLs et al. [15] aimed to validate the recently published Global Lung Initiative (GLI) reference values for spirometry [16] in comparison with the spirometry reference values published by ZAPLETAL et al. [17]. HÜls et al. [15] assessed 1843 4-18 year-old-children from the LUNOKID (Lungenfunktions-Normalwerte bei Kindern in Deutschland) study under field conditions in three German communities. They found that lung function not only depended on the child's height, as in the Zapletal equation, but also depended in a nonlinear way on age, as in the GLI equation. Compared with the GLI data, a significantly smaller percentage of children than the expected $5 \%(0.9-1.8 \%$ depending on age $)$ had a forced expiratory volume in $1 \mathrm{~s}$ (FEV1) below the lower limit of normal.

INNOCENTI et al. [18] reported a reference equation for the 6-min walk test calculated from 261 healthy Italian children aged 6-11 years. When adjusting for the other covariates, age, height and weight were independently correlated with the 6-min walk distance and explained $25 \%$ of the variability in the distance covered.

MeNOU et al. [19] provided reference values for offline exhaled nitric oxide obtained from 88 healthy school-age French children. They also measured nasal nitric oxide in 31 children. Collecting gas samples from the upper and lower airways in an offline manner has the advantage of improving screening and follow-up for respiratory diseases.

\section{Functional monitoring of sleep disordered breathing}

VAN HOLSBEKE et al. [20] investigated whether a three-dimensional pharyngeal airway reconstruction built from computed tomography (CT) images predicted obstructive sleep apnoea (OSA) severity better than clinical markers in 23 children with OSA diagnosed using polysomnography and 10 controls. Functional imaging variables highly correlated with OSA severity and were a more powerful correlate of upper airway patency than clinical scores. These data also suggested that the new technique might detect differences in the upper airway of those subjects who will not benefit from local upper airway treatment.

KHIRANi et al. [21] evaluated whether routine carbon dioxide measurement might be useful during 221 polygraphies in children with suspected OSA (72\%), neuromuscular disease $(21 \%)$ or lung disease $(7 \%)$. The percentage of hypercapnic patients ranged $20-60 \%$, did not differ between groups and correlated weakly with the apnoea/hypopnoea index and oxygenation indices, suggesting that a systematic nocturnal carbon dioxide recording is useful in all children presenting with sleep disordered breathing, whatever the underlying disease. 
Alonso-Alvarez et al. [22] studied the reliability of home respiratory polygraphy for diagnosing sleep apnoea-hypopnoea syndrome (SAHS) in 50 children with a mean age of 5.3 years. Compared with polysomnography performed in a sleep lab, when polygraphy was performed at home or in the laboratory, several SAHS indices yielded a large area under the receiver operating characteristic curve, confirming that home respiratory polygraphy is a useful technique for diagnosing SAHS in children.

\section{Paediatric asthma and allergy \\ Preschool wheeze}

It all starts in the womb: asthma exacerbations during pregnancy and oral corticosteroid use have a significant effect on birth weight and pre-term delivery. Equally important is moderate-to-severe asthma during pregnancy, which is associated with an increased risk for small-for-gestational-age babies [23], possibly leading to lower lung function in adult life [24]. In a large birth cohort study, HALLBERG et al. [25] demonstrated that early onset asthma also resulted in lower lung function in adolescence, even if the symptoms were transient. In another birth cohort study, LøDRUP-CARLSEN et al. [26] showed that lung function trajectories in atopic disease start from birth and thereafter remain unchanged. Hence, a low lung function trajectory in atopic asthma will lead to lower lung function in adolescence, a phenomenon called "tracking". LUKKARINEN et al. [27] demonstrated that atopic sensitisation at first wheeze is associated with longer daily asthma controller therapy. Having better ways of predicting asthma would make it easier to treat the appropriate wheezy children subgroup.

Although volatile organic compounds can now be collected and analysed from exhaled breath, as yet no data have proved their clinical value in diagnosing wheezing in preschool children [28]. Most asthma episodes are provoked by viral infections, which may be mistreated by prescribing antibiotics. GEDIK et al. [29] reported that diagnosing childhood asthma early and starting timely treatment with anti-inflammatory medications resulted in a marked decrease in antibiotic use. STENBERG HAMmar et al. [30] suggested that apart from viral infections, bacterial pathogens, including Moraxella catarrhalis, may also act as triggers of acute wheeze in preschool children.

KLOK et al. [31] measured adherence to inhaled corticosteroids daily for 12 months in 2-6-year-old children using Smartinhaler (Nexus 6, Auckland, New Zealand) devices. They found a surprisingly high median adherence rate of $87 \%$ (interquartile range 61-94\%). All studied children were taking part in an extensive self-management training programme [32]. It has been recommended that drug administrations should be reduced as a way of increasing adherence. However, in this young age group, KLOK et al. [33] also showed that although once-daily dosing was associated with slightly higher adherence rates, there was an increase in the number of days without medication; they thus concluded that reducing corticosteroid therapy from twice to once daily does not improve adherence in children receiving guideline-based asthma care.

\section{Asthma control}

According to recent asthma treatment standards, treatments primarily aim to control asthma; a recent review attributes a lack of control to many factors [34]. IlyenKova et al. [35] demonstrated that uncontrolled asthma may be due to infection with Mycoplasma pneumoniae or Chlamydia pneumoniae. KREGGEMIJER et al. [36] again emphasised the need to get the basics of asthma treatment right, clarifying that true therapy-resistant asthma is a rare event. In $97 \%$ of tested children in a hospital-based asthma clinic, asthma improved when attention focused on comorbidities ("asthma plus"), a wrong diagnosis ("not asthma at all"), incorrect inhaler technique, ongoing exposure to environmental triggers and poor adherence to treatment. Growing evidence indicates a positive correlation between asthma and obesity in children and adults. Despite these emerging findings, while reporting blood leptin and adiponectin levels to be higher in obese than in non-obese asthma patients, WAHAB et al. [37] found no significant difference in blood protein levels with stratification for asthma severity. Fascinating new data have now become available from the child asthma control test (cACT). Parents' and children's cACT scores differ significantly, with parents tending to under-report and children to over-report [38]. In a randomised controlled trial, the BATMAN (Better Asthma Treatment: Monitoring with ACT and Nitric oxide) study, VoOREND-VAN BERGEN et al. [39] showed that monthly cACT testing led to a reduction in inhaled corticosteroid use but left asthma control unchanged.

\section{Severe asthma}

Children with severe asthma are a difficult group to treat, and an especially challenging task is to identify the success of a particular drug. In an effort to seek information on individual drug responses, VAN SPRANG et al. [40] analysed lung functions (peak expiratory flow) twice daily and compared responses to medication changes. While the concordance between this method and the clinical response was poor, the authors postulated that identifying both concordant (true-positive and true-negative) and discordant (false-positive 
and false-negative) subgroups could be valuable in supporting the effectiveness of inhaled corticosteroids or identifying groups for whom other factors might be more effective.

Treating gastro-oesophageal reflux with proton pump inhibitors in children with asthma generally yields disappointing results. Accordingly, AL-BiLTAGr et al. [41] showed that domperidone plus esomeprazole was more effective than esomeprazole alone in improving the endoscopic reflux score, cACT scores and FEV1 (\% predicted), but only in children with difficult-to-treat asthma.

Anti-immunoglobulin $\mathrm{E}$ therapy is a relatively new treatment modality now also available for asthmatic children $<12$ years of age. NAmAzova-BARANOva et al. [42] and Kopp et al. [43] reported that antiimmunoglobulin E therapy is associated with improved quality of life, fewer asthma exacerbations, but not with increased physical activity.

Finally, data are now available that show how long it is until a child is fit to fly again after an asthma exacerbation requiring oxygen administration. PEÑA et al. [44] reported that all children hospitalised for asthma exacerbations requiring oxygen administration passed the hypoxia test $48 \mathrm{~h}$ after oxygen removal.

\section{Cystic fibrosis}

\section{Lung function and imaging}

Early lung disease in CF has attracted much attention during the past decade owing to information from several studies showing that lung disease starts early in life before conventional methods, such as spirometry, can be used to measure lung function. Ample evidence confirms that MBW with SF6 as a tracer gas is a sensitive method for detecting early lung disease in children with CF from preschool age; however, few studies exist in newborn babies [45]. In a recent study, LCI proved age-dependent up to 6 years of age but not thereafter [46]. The introduction of newborn screening and diagnosis 4-6 weeks after birth has made it possible to investigate the lungs exposed to infection during this short time.

In 23 infants newly diagnosed with CF at a median age of 6 weeks, KIENINGER et al. [47] found LCI levels within the normal range in 22 out of 23 children. In contrast, STAHL et al. [48] found a significantly higher LCI in CF children with a mean age of $1.3 \pm 1.0$ years compared with controls, implicating the importance of screening and early treatment to keep the lungs normal.

THIA et al. [49], from the London Cystic Fibrosis Collaborative group, followed 55 CF infants diagnosed using newborn screening and a control group, and measured FEV0.5 and LCI using MBW SF6 at ages 3 months, 1 year and 2 years. FEV 0.5 was significantly decreased at 3 months of age but improved at 1 and 2 years, whereas LCI was higher in CF children than in the healthy control group at 1 and 2 years but remained stable over time. How this study compares with others showing progressive structural lung disease remains unclear.

RAMSEY et al. [50], from the AREST (Australian Respiratory Early Surveillance Team) study group, assessed lung function at school age (median age 6.4 years) in children with CF detected using newborn screening followed by repeated high-resolution computed tomography (HRCT) and bronchoalveolar lavage (BAL) at age 3 months to 2 years. The presence of air trapping on HRCT, lower airway infection and free elastase in BAL fluid in infancy were associated with reduced lung function at school age. In a previous article, this group had already shown that free elastase in BAL fluid early in life is associated with bronchiectasis in preschool years [51].

The London group has shown that pathology indicative CT and LCI develop early in life and can be used to detect early lung disease and predict lower lung function at a later age $[52,53]$. As in previous years, the argument for bringing the $\mathrm{CT}$ scan and MBW forward as clinical end-points and relating these investigations to the various clinical outcomes is still hot topic [54]. In two studies, SHEIKH and co-workers $[55,56]$ showed that HRCT during general anaesthesia and infant lung function testing (raised volume thoraco-abdominal compression technique) during sedation improved after intravenous antibiotic therapy in at total of 49 infants ( 21 in one study and 28 in the other) with CF at a mean age of 21 weeks, underscoring that untreated $\mathrm{CF}$ is a progressive disease.

Welsh et al. [57] and AL-KhATHLAn et al. [58] investigated the effect of i.v. antibiotics on LCI during pulmonary exacerbations in older children. While WELSH et al. [57] found an improvement in LCI after treatment, AL-KHATHLAN et al. [58] did not. These contrasting results may reflect the different severity levels of lung disease at the start of treatment.

An important requirement is a reliable and valid scoring system for CT scans. KuO et al. [59] compared two scoring systems for bronchiectasis in early CF lung disease, the CF-CT scoring module and the airway/artery (AA) ratio. When used to score 20 patients at 2-3 years of age and later at 4-5 years of age, the AA ratio detected significantly less bronchiectasis in the younger than the older age group, perhaps because the 
younger group included fewer AA pairs for analysis than the older group and because the CF-CT scoring system included airways deemed abnormal not accompanied by an artery. BorTOLUZZI et al. [60] related the CT score at a mean age of 8 years to the risk of subsequent Pseudomonas aeruginosa infection and found a significant association between early lung structural damage and later chronic P. aeruginosa infection.

MBW with nitrogen $\left(\mathrm{N}_{2}\right)$ is a sensitive but time-consuming method for detecting ventilation inhomogeneity in CF patients. To investigate this drawback, HoulTz et al. [61] assessed whether SBW either after a vital capacity manoeuvre (SBW VC SnIII) or after inspiring $1 \mathrm{~L}$ of pure oxygen (SBW FRC+1L SnIII) was as sensitive as LCI in detecting ventilation inhomogeneity. The results showed that the SBW FRC+1L SnIII was nearly as sensitive as LCI, whereas the SBW VC SnIII analysis was not. LINDBLAD et al. [62] measured LCI (MBW $\mathrm{N}_{2}$ ) over 1 year and showed a larger variation of LCI in patients with lower FEV1 and higher LCI, but similar values when related to the LCI level.

\section{Exercise and physiotherapy}

Physiotherapy is the most time-consuming part of the CF treatment routine and has a known low adherence over time. The effect of physiotherapy on lung function is difficult to evaluate both in the shortand long-term. A recent Cochrane review investigating the benefit of physiotherapy in CF patients identified few randomised studies that evaluated the various physiotherapy methods; some studies showed positive short-term effects but none were able to show long-term effects [63].

Using electrical impedance tomography, WETTSTEIN et al. [64] investigated the effect of continuous positive airway pressure (CPAP) and positive expiratory pressure (PEP) on gravity-dependent ventilation in different body positions (sitting and right lateral position) in nine adult CF patients and 11 healthy controls during spontaneous breathing. In the sitting position, both lungs were equally ventilated, whereas in the right lateral position, dependent ventilation increased to $64 \%$ in healthy subjects and $65 \%$ in CF patients. CPAP enhanced the beneficial effect in both groups but PEP neutralised the improvement, suggesting CPAP and PEP cannot be used interchangeably.

In a study designed to measure short-term physiotherapy-induced changes with MBW $\mathrm{N}_{2}$, PFLEGER et al. [65] found a variable LCI response, either an increased or decreased ventilation inhomogeneity, probably the result of opening up previously poorly ventilated areas.

Exercise in CF is increasingly recognised to be important to the maintenance of good lung function and bone health, and to the patient's sense of wellbeing $[66,67]$. The following three presentations at the ERS congress discussed physical activity levels and the potential benefits induced by an active lifestyle. Using a questionnaire, KARAPANAGIOTIS et al. [68] investigated the exercise and sports habits of children with CF who were 6-18 years of age, and found activity levels to be similar to healthy peers. SAVI et al. [69] assessed hand-grip strength and daily activity levels as measured using a SenseWear accelerometer (BodyMedia Inc., Pittsburgh, PA, USA). Patients were studied at rest and during a symptom-limited incremental exercise test (cardiopulmonary exercise testing). The authors found a close relationship between vigorous daily activity and cardiopulmonary exercise testing, and between moderate and vigorous daily activity and hand-grip strength. In a small sample of patients who underwent a 1-month physical fitness programme, LASKINE et al. [70] found that regular exercise can decrease airway inflammation.

\section{Microbiology}

Several studies have found anaerobic bacterial growth in CF airways [71, 72]. The clinical importance of this finding is unclear. BERTELSEN et al. [73] reported that in airway epithelial cells pre-incubated with Prevotella spp. under anaerobic conditions, interleukin-8 release was reduced after exposure to Prevotella nigrescens followed by $P$. aeruginosa, indicating that anaerobic bacteria in the airways may have anti-inflammatory properties.

The pattern of pathogens in the lungs is changing over time, with new pathogens coming into focus [74]. An increasing problem with Mycobacterium abscessus infection was recognised in a study by KuMAR et al. [75], who showed that incidence increased from 1.5 to $2.7 \%$ from 2007 to 2012, whereas the incidences of other non-tuberculous mycobacteria infections decreased.

GODBERT and Briault [76] and RobSOn et al. [77] compared patients before and after acquiring chronic Achromobacter xylosoxidans infection. Both groups detected an increased exacerbation rate, and GODBERT et al. [76] demonstrated a faster decrease in FEV1 in A. xylosoxidans colonised patients compared with uncolonised controls.

FUSTIK et al. [78] and VANDERHELST et al. [79] showed that methicillin-resistant Staphylococcus aureus can be eradicated some time after the first isolation. They used different eradication policies: FusTiK et al. [78] 
administered two oral antibiotics for 4 weeks plus nebulised vancomycin for 2 weeks; VANDERHELST et al. [79] administered two oral antibiotics for 6 months.

Allergic bronchopulmonary aspergillosis is an increasing problem in the CF population and its treatment with long-term high-dose prednisone predisposes to diabetes and decreased bone mineral density. AMADDEO et al. [80] reported a steroid-sparing effect of omalizumab in four CF patients with allergic bronchopulmonary aspergillosis; steroid treatment could be withdrawn within a couple of months.

The association between viral respiratory infections, in particular rhinovirus, and pulmonary exacerbations is well described [81, 82]. SHAH et al. [83] found no differences in the pathogenicity of individual rhinovirus groups, but virus-associated exacerbations had a greater impact on lung function, length of treatment and time to next exacerbation than exacerbations in which no rhinovirus was detected.

\section{Complications}

Fatigue is a complication that is rarely reported in the literature and when discussed clinically, is attributed to lung function and inflammation. JARAD et al. [84] evaluated adult CF patients using three questionnaires for fatigue: the Chalder fatigue questionnaire, the St Mary's Hospital sleep questionnaire, and the scaled General Health and Hillier questionnaire (GHQ). Males and females with CF had significantly higher fatigue scores than healthy controls, with a close correlation between the fatigue score and the sleep questionnaire and GHQ scores, but not with objective measures such as FEV1 or inflammatory variables.

Another important clinical problem in CF is the involvement of the sinuses. Di Cicco et al. [85] studied 882 children with CF over 12 years to detect sinonasal mucoceles. 38 children benefitted from endoscopic sinus surgery; in all of them, clinical improvements as well as a reduction in the use of antibiotics were achieved.

In a study comparing the sweat chloride levels of healthy smokers and smokers with COPD with those of healthy controls, RAJU et al. [86] showed that smokers had significantly higher sweat chloride levels than normal controls. CF transmembrane conductance regulator (CFTR) activity was also decreased in human bronchial epithelial cells exposed to plasma from smokers, suggesting that a circulating factor can confer CFTR dysfunction. This finding indicates that cigarette smoke can cause systemic CFTR dysfunction, thus providing a potential explanation for the incidence of CFTR-associated disorders in smokers.

\section{Paediatric respiratory infection and immunology \\ Viral infections}

In infants, respiratory syncytial virus (RSV) bronchiolitis remains a major cause of morbidity, with few or no treatment options for acutely ill infants other than supportive care. In a mouse model, antibodymediated neutrophil depletion in animals infected with a clinical RSV strain (isolate A2001/2-20) resulted in less pulmonary tumour necrosis factor and reduced airway mucin production in the lung [87]. Because neutrophils are a central component in the RSV-triggered inflammatory response, SAINT et al. [88] studied the role of neutrophils in mediating RSV clearance. In purified blood neutrophils, they found evidence to suggest that neutrophils initially internalise the destroyed RSV. Airway neutrophilia in RSV bronchiolitis is triggered by infection in the airway epithelium. As knockdown of the E3 ubiquitin ligase RNF168 in airway epithelial cells supports intracellular RSV replication, JEYATHESWARAN et al. [89] infected A549 cells with RSV and assessed RNF168 protein expression by Western blot. Overall, after RSV infection, airway cells underwent significant RNF168 expression downregulation. If this event happened in vivo, it could be associated with impaired immune clearance. By contrast, the antiviral protein interferon- $\gamma$ increased RNF168 expression.

Prematurity increases the risk of developing clinically severe RSV bronchiolitis. To assess whether some premature infants are genetically predisposed to clinical bronchiolitis, DRYSDALE et al. [90] followed infants discharged from a single maternity unit, and tested nasopharyngeal aspirates whenever infants had a lower respiratory tract infection. When these data were linked to 11 single nucleotide polymorphisms, an association was found between an single nucleotide polymorphisms in ADAM33 and increased risk of developing an RSV-associated lower respiratory tract infection. Hence, both genetic factors and prematurity may enhance vulnerability to RSV infection.

In older infants and preschool children, RV is a major trigger of lower respiratory tract symptoms. In a prospective study of 152 infants born at $<36$ weeks' gestation, RV-associated lower respiratory tract infections were linked with increased health-related costs of care during infancy, and RV-infected infants suffered greater chronic respiratory morbidity [91]. A study by MACK et al. [92] suggests that these symptomatic RV infections are the tip of a very large iceberg. The researchers collected weekly nasal swabs from 40 term infants over 12 months. RV was found in $27 \%$ of the 1298 swabs analysed, and in $79 \%$ of cases in which RV was detected, the child was clinically asymptomatic. In contrast, KANIK et al. [93] focused 
on the symptomatic spectrum of RV infection. Nasal swabs were taken from 275 children hospitalised for respiratory symptoms in a Turkish tertiary care centre over 12 months. Rhinovirus was the most frequent virus isolated (8.7\%). Dual infection with RV and RSV may also be clinically important given that in a study including 1992 hospitalised episodes of acute respiratory infections in Vietnamese children, dual infection was found to be associated with an increased risk of lower respiratory symptoms [94].

\section{Bacterial infections}

Empyema as a complication of bacterial pneumonia is an important cause of morbidity and mortality in children, and is most frequently caused by Streptococcus pneumoniae. There is some concern that although the 7-valent pneumococcal conjugate vaccine has significantly decreased pneumonia admissions, serotype replacement may have increased severe empyema [95]. Differences in serotype may explain the differences in the clinical course of empyema between countries, although a more likely explanation may be the variation in its clinical management. In a retrospective study of 63 children admitted to a Guatemalan hospital with pneumonia and empyema, EsCOBAR et al. [96] reported that $24 \%$ of children underwent open thoracotomy and decortication, with an overall mean hospital stay of 23 days. In contrast, ProEsMANS et al. [97] reported a median hospital stay of 13 days in children treated initially with a chest drain and fibrinolytics in Belgium.

One complication associated with empyema is necrotising pneumonia, previously reported to be associated with a prolonged hospital stay [98]. Reassuring evidence that necrotising pneumonia, independent of empyema, does not add to morbidity was provided by BLANCHON et al. [99], who compared outcomes from 23 children with empyema without necrotising pneumonia (using a CT scan) with those from 24 children with both empyema and necrotising pneumonia. No difference was found in the children's symptoms, microbiology (S. pneumoniae in 14 and 20, respectively), need for lung surgery or length of hospital stay. The complication rate was similar for the two groups.

Although bacterial infection is the major cause of empyema in children, other stimuli may play a role in increasing vulnerability to bacterial adhesion and invasion. For example, it was reported that cigarette smoke upregulates $S$. pneumoniae adhesion to airway cells via a platelet-activating factor receptordependent interaction [100]. In this model, S. pneumoniae hijacks the platelet-activating factor receptor to adhere to host cells and then enters cells as the receptor is internalised [101]. Viruses such as rhinovirus also upregulate bacterial adhesion to lower airway cells [102]. More obscure viruses may also be important in predisposing to empyema. In a prospective study of 28 children in a French paediatric intensive care unit with parapneumonic empyema, a bacterial pathogen was isolated from the pleural fluid $(19 \times$ S. pneumoniae and $2 \times S$. aureus) in most cases, and in many of these a respiratory virus was isolated from a concomitant nasal sample (rhinovirus, bocavirus, parainfluenza, human coronavirus, RSV, adenovirus). In six of the children with S. pneumoniae empyema, the pleural fluid contained the new torque teno mini virus [103]. To date it remains unclear whether torque teno mini virus increases bacterial adhesion to airway cells; this is an area requiring further study.

\section{Neonatology and paediatric intensive care \\ Neonatology}

There is increasing awareness that in preterm infants with immature lungs, initial ventilatory management may play a crucial role in respiratory disease development in the neonatal period and may even affect the long-term outcome. In this respect, the first few hours of life may be viewed as "golden hours" for the lung and cutting-edge neonatal research has focused on delivery room practices and on optimisation of alveolar and vascular transition at birth. Recently, it was suggested that delaying cord clamping until after the onset of ventilation will markedly improve cardiovascular function by increasing pulmonary blood flow and thereby keeping the cardiac output stable, leading to a smoother transition to extrauterine life [104]. These are intriguing data that improve our understanding but also challenge current practice.

Effective ventilation is fundamental to successful resuscitation of the compromised newborn. When they evaluated the use of a respiratory function monitor during resuscitation of preterm infants, MiLNER et al. [105] found that most trainees considered the monitor helpful, but its usefulness depended on the level of experience of the user. Neonates are usually resuscitated with a facial mask in the delivery room. BHAT et al. [106] have demonstrated that increasing peak inspiratory pressure during the first five inflations leads to more effective ventilation, with tidal volumes exceeding anatomical dead space. A short nasal tube has been suggested as an alternative interface to avoid the leak and airway obstruction commonly seen during mask ventilation. Two randomised controlled trials were reported in 2013, which compared mask use with a nasal tube and included a total of 507 preterm infants; neither showed differences in intubation rates and shortterm outcomes [107, 108]. 
Spontaneously breathing preterm infants can be safely stabilised using noninvasive respiratory support, such as nasal CPAP, at birth. This requires a strategy of surfactant administration at a later stage, and new techniques for surfactant therapy are gaining intense interest. Minimally invasive surfactant therapy, in which a narrow-bore catheter is inserted into the trachea, has been studied in an open feasibility trial and has been shown to result in a sustained reduction in oxygen requirement and a decreased need for intubation in the most preterm infants (25-28 weeks gestation) [109]. In a randomised trial of 200 preterm infants, which compared the thin catheter technique (referred to as Take Care in this study) with the InSurE (Intubate, Surfactant, Extubate) approach, the Take Care technique significantly reduced the need for mechanical ventilation as well as the bronchopulmonary dysplasia (BPD) rate compared with InSurE [110]. In a meta-analysis of seven studies comprising 3289 infants, FISCHER and BÜHRER [111] investigated how strategies to avoid mechanical ventilation influence the incidence of BPD. Their meta-analysis showed that avoiding intubation and mechanical ventilation significantly reduced $\mathrm{BPD}$, although the effect size was moderate (OR 0.83, number needed to treat 35). This finding is intriguing and requires further investigation that addresses both the potential benefits of spontaneous breathing, particularly during surfactant administration, and the need for analgesia and sedation during direct laryngoscopy. A centre using the thin catheter technique for surfactant therapy as part of a more extensive protocol for gentle delivery room management, reported a follow-up of infants born $<26$ weeks and showed that neurocognitive outcome was normal in $70 \%$ [112].

The revised European consensus guidelines on management of neonatal respiratory distress syndrome now recommend CPAP from birth and early rescue surfactant followed by rapid extubation when possible [113]. These guidelines also address oxygen supplementation beyond stabilisation and recommend a saturation target of $90-95 \%$ for preterm infants receiving oxygen. This target is in line with the results from the recently published BOOST (Benefits of Oxygen Saturation Targeting) II trial, which reported that targeting oxygen saturation below $90 \%$ in extremely preterm infants is associated with an increased risk of death [114]. This large, international, randomised trial is now the basis for revised protocols regarding oxygen supplementation in neonates around the world.

The quest for improving both short- and long-term pulmonary outcomes following preterm birth continues. POLYCARPOU et al. [115] reported results from a randomised trial of oral L-arginine supplementation to very low birth weight infants. In this small trial of 74 infants, the nitric oxide precursor L-arginine increased survival without BPD. ZIVANOVIC et al. [116] presented lung function data from a subset of children from UKOS (United Kingdom Oscillation Study) at 12 years of age, which suggested that small airway function deteriorated over time in children born very prematurely and that this happened regardless of previous BPD. Conversely, using HRCT in a small group of adult BPD survivors, CASKEY et al. [117] found significantly more structural abnormalities in BPD survivors than in individuals born preterm without BPD. A systematic review showed that preterm survivors are at risk of long-term deficits in FEV1, even those who do not develop BPD [118].

\section{Paediatric intensive care}

High-flow nasal cannula (HFNC) is a respiratory support modality that has been rapidly established in clinical practice, both for neonatal and paediatric patients. The benefits of HFNC include easier nursing care, increased comfort and less severe nasal trauma than with nasal CPAP. Disadvantages include a lack of airway pressure control and the potential risk of inadvertent high pressure if the nostrils are occluded, a concern primarily for smaller babies. A recently published state-of-the-art review regards HFNC as a valuable treatment tool in bronchiolitis [119]. In a prospective observational study, KRIVEC et al. [120] enrolled 39 children $\leqslant 24$ months of age with acute viral bronchiolitis and showed that HFNC effectively improved physiological respiration and gas exchange variables. These results are in line with other recent clinical trials, which demonstrated improved breathing patterns and rapid respiratory muscle uploading after HFNC treatment for viral bronchiolitis in infants [121].

HFNC is an increasingly popular alternative to nasal CPAP for noninvasive respiratory support in preterm infants, but until now efficacy and safety data have been lacking. In a multicentre study, designed as a noninferiority trial, 303 infants were randomised post-extubation to either HFNC or nasal CPAP [122]. The primary outcome measure was treatment failure within 7 days; HFNC was close to the non-inferiority margin, but almost half of the infants in whom HFNC treatment failed could be successfully rescued with CPAP without reintubation. Apart from a significantly lower incidence of nasal trauma in the HFNC group, no differences were found for serious adverse events, thus providing good evidence that HFNC is a safe treatment alternative, even in the smallest infants. 


\section{Paediatric respiratory epidemiology}

\section{Early life risk and protective factors for respiratory disorders}

In recent years, intensive research has focused on early life risk and protective factors for respiratory disorders [123]. The information gained has facilitated a number of ongoing birth cohort studies prospectively collecting information on possible risk and protective factors commencing at pregnancy.

Combining data from birth cohorts participating in the CHICOS (Developing a Child Cohort Research Strategy for Europe) project, ZugNA et al. [124] found an association between pre-eclampsia, being overweight and obese pre-pregnancy, and recurrent wheeze in the first 2 years of life. Other studies have recently confirmed the association between pre-pregnancy obesity and maternal weight gain in pregnancy with wheezing in the offspring [125]; however, rare conditions such as pre-eclampsia need to be investigated in collaborative studies in larger populations and wider settings.

Also in the CHICOS project, the meta-analysis of SONNENSCHEIN-VAN DER VOORT et al. [126] demonstrated an association between infant weight gain and preschool wheezing and asthma at school age.

SONNenschein-VAn der Voort et al. [127], De Korte-De Boer et al. [128], and Pike et al. [129] conducted cohort studies assessing the relationship between early growth (measured as weight and weight gain, height and height gain, and body mass index (BMI)) and later wheezing/asthma or lung function; others have also recently published their results [130]. The findings appear to be contradictory. One reason for the noted discrepancies could be the methods used to evaluate growth rate. In a study investigating the causal effect of BMI, fat and lean mass on childhood asthma, GranELL et al. [131] used Mendelian randomisation. They were able to do so because genome-wide studies have identified 32 independent loci associated with BMI [132]. The estimated causal risk ratio (95\% CI) for the effect of BMI on asthma at 7 years of age was 1.55 (1.16-2.07), with a stronger effect in girls.

In their study conducted during the first year of life of children participating in the Swedish birth cohort BAMSE (Barn/Children, Allergy, Milieu, Stockholm, Epidemiological survey), SchUlTz et al. [133] found that exposure to traffic-related air pollution (nitrogen oxides) negatively affects lung function in adolescence, thus confirming the results of a previous study performed in 8-year-old children [134]. The effects of chronic exposure to air pollution on children's respiratory health have recently been investigated in the PATY (Pollution and the Young) project, which assembled data from children in 12 countries and found positive associations between the average particulate matter with an aerodynamic diameter of $10 \mu \mathrm{m}$ (PM10) concentration and phlegm, bronchitis and cough [135].

Another major "environmental" factor in early life is nutrition. Numerous studies have investigated the relationship between infant feeding practices and respiratory outcomes. In the International Study on Wheezing in Infants (covering 22 centres in South America and Europe), GARCIA-MARCOS et al. [136] found that the protective effect of breastfeeding against recurrent wheeze during the first year of life varies depending on family history of atopy (breastfeeding was increasingly more protective if the family history was less atopic). Conversely, DOGARU et al. [137] found no clear evidence of a protective effect of breastfeeding against allergic rhinoconjunctivitis in children in the Leicester (UK) cohort study. GoKsör et al. [138] confirmed that the protective effect of early (before 9 months of life) fish introduction into an infant's diet against wheezing in early childhood is also present for atopic asthma at school age. A recent systematic review, however, concluded that the evidence is inconsistent from the epidemiological studies investigating the effects of fish intake during infancy and childhood on atopic outcomes in infants or children, and that further studies are needed [139]. Finally, in the context of the PASTURE (Protection against Allergies Study in Rural Environments) birth cohort study conducted in five European countries, RoDuiT et al. [140] showed that an increased diversity of foods introduced in the first year of life had a significant protective effect against the later development of asthma, food allergy and food sensitisation, and that reduced food diversity was associated with reduced expression of Foxp3. Although the studies by GOKSÖR et al. [138] and RoDUIT et al. [140] were conducted in prospective birth cohorts and adjusted for confounders, reverse causation cannot be completely excluded.

\section{Longitudinal studies and the natural history of respiratory diseases}

Longitudinal studies offer important clues into the natural history of respiratory diseases; they track certain asthma features from childhood to adulthood, include disease severity and lung function impairment, and stress the importance of characterising the clinical course of the disease early in life [141].

In a study designed to investigate whether factors associated with wheeze are linked with a changing trajectory of lung function tracking, TURNER et al. [142] observed a significant relationship between maternal asthma and reduced lung function from 1 to 18 years of age, infant onset of atopy and reduced 
lung function from 6 to 18 years of age, flow limitation at 1 month of age, and reduced lung function $\leqslant 6$ years of age.

WARM et al. [143] evaluated the incidence and persistence of allergic sensitisation in the OLIN (Obstructive Lung Disease in Northern Sweden) paediatric cohort and found that the prevalence of any positive skinprick test increased significantly with age, from $21 \%$ at 8 years of age to $42 \%$ at 19 years of age. Early onset allergic sensitisation was associated with multi-sensitisation in young adulthood.

In a study of adolescents who had outgrown childhood wheezing, MARSHALl et al. [144] found that those with previous "persistent multiple trigger wheeze" had higher sputum total cell counts and eosinophilic inflammation. Unexpectedly, eosinophilic inflammation was also present in subjects who had outgrown "transient viral wheeze".

Presenting data from the MeDALL (Mechanisms of the Development of Allergy) study (12 ongoing European birth cohorts), PINART et al. [145] showed that eczema, rhinitis and asthma coexist in the same child both at 4 and 8 years of age, more often than would have been expected if these were independent entities. The similar comorbidity pattern in those with and without a parental history of atopy or IgE sensitisation suggests that these relationships involve mechanisms other than atopy.

DAMGAARD et al. [146] looked at the relationship between gestational age (GA) at birth and use of asthma medication in a Danish register of all infants born between 1980 and 2009 (1 790241 individuals). They found a strong dose-response association between the two during infancy, with ORs of 3.87 in GA 23-27 weeks, 2.34 in GA 28-31 weeks, and 1.59 in GA 32-36 weeks, compared with infants born at term. The relationship weakened gradually with age and was not statistically significant in 25-31-year-old adults. Whether the strength of this association increases again later in adulthood remains unclear, and requires further investigation.

\section{Pneumococcal vaccine-induced changes in childhood pneumonia}

Routine vaccination has greatly reduced the pneumococcal disease burden in children worldwide, although available data mainly refer to developed countries [147]. In 2010, the 10-valent pneumococcal non-typeable Haemophilus influenzae protein D conjugate vaccine was introduced to the national immunisation programme in Brasil. Using data from an open-access database, PINTO et al. [148] showed that childhood bacterial pneumonia hospitalisation rates decreased by $29 \%$ thereafter, whereas bronchitis/bronchiolitis rates did not decrease in the same period.

\section{Studies in twins}

Studies in twins are a powerful tool to control for familial confounding due to genetic or environmental factors.

To examine the association between early menarche (before 12 years of age) and risk of post-menarchal asthma, LieBEROTH et al. [149] prospectively studied 10648 female twins from the Danish Twin Registry. The risk of asthma increased by $8 \%(0-15 \%)$ per year of earlier menarche occurrence. Among 167 twin pairs discordant for asthma, early menarche tended to be more common in the asthmatic twin than in her nonasthmatic co-twin (12 versus $9.6 \%$; nonsignificant), suggesting that non-genetic factors could influence the association. This needs to be confirmed in a large number of discordant twins.

In recent years, several studies have provided valuable insights into the relationship between psychosocial factors and asthma morbidity [150]. HAVLAND et al. [151] investigated the association between maternal anxiety and offspring asthma in a "children of twin"-design study. Maternal anxiety was significantly associated with both asthma at adolescence reported by the mother and breathlessness reported by the adolescents themselves, but not with register-based asthma diagnosis or medications. The children-of-twin analysis indicated that the association depends on familial confounding; possible responsible factors include heritable personality traits associated with anxiety and subjective asthma measures.

\section{Paediatric bronchology}

Several studies addressed the role of bronchoscopy in managing intrinsic airway obstruction. SCHRAMm et al. [152] presented the results of a nation-wide survey addressing current practice for airway foreign body (FB) management in Germany. They approached paediatricians, anaesthetists, ear, nose and throat surgeons, and internists; 255 questionnaires were returned, the majority from anaesthetists and paediatricians. For confirmation of FB aspiration, 74\% preferred flexible bronchoscopy. For FB removal, 43\% preferred a rigid instrument, 30\% routinely used flexible and rigid instruments, and 20\% preferred flexible bronchoscopy. Almost $40 \%$ of the responding institutions had no specific standard operating procedure. It is difficult to compare these results with previously published data. Apart from a few studies describing single-centre 
experiences, only one large multicentre study has been published so far [153]. In this survey, $41 \%$ of the addressed European centres returned the questionnaire sent to 220 members of the ERS Paediatric Assembly. During a single year, these institutions had performed 4587 flexible and 2859 rigid bronchoscopies. In centres using only rigid bronchoscopy, $37 \%$ of examinations were indicated for "FB inhalation".

In the past 20 years, technical developments have allowed for major progress in paediatric bronchology. Some authors have also recommended the use of flexible bronchoscopes for the management of FB aspiration in children $[154,155]$, and in some centres this has become the most frequently used option. In this context, AsLAN et al. [156] presented a case documenting the importance of follow-up flexible bronchoscopy, even after successful FB removal with a rigid instrument. No recent multicentre study has properly documented the trends in managing FB aspiration or other advances in paediatric bronchoscopy.

In a retrospective study, KuT et al. [157] evaluated endobronchial obstructions detected during 2555 flexible bronchoscopies. The most frequent obstructive lesions were aspirated FBs, followed by endobronchial tuberculosis, mucous plugs and granulation tissue. The authors suggested that bronchoscopy performed early in the presence of clinical or radiological findings suggesting an endobronchial obstruction can prevent morbidity, mortality and also unnecessary treatment.

CAKIR et al. [158] evaluated airway involvement in a large group of children with tuberculosis. Among 492 children with pulmonary tuberculosis, 167 (29\%) underwent flexible bronchoscopy. Airway involvement was found in $55 \%$ of patients, more frequently in children with resistant mycobacteria. Combining gastric aspirates and BAL increased the bacteriological yield. This large study confirms the results from a smaller group of patients, previously published by the same group [159].

A unique report by REITER et al. [160] demonstrated two cases of intrauterine fetal bronchoscopies performed in children with suspected bronchial atresia expected to be incompatible with life. Although this report suggests that intrauterine bronchoscopic intervention could be useful in selected cases, the authors warned about the significant associated risk and recommended that such interventions should be reserved for cases in which extrauterine viability is otherwise unlikely. Greater experience with such techniques can be expected in the near future. Since the publication of the preliminary report by this group [161], another report has indicated that bilobar bronchial atresia can be successfully managed using fetoscopy and fetal bronchoscopy with a diode laser therapy [162].

Whilst earlier BAL studies have confirmed neutrophilic inflammation in patients with protracted bacterial bronchitis (PBB), less is known about the level and type of inflammation within the airway wall. Douros et al. [163] presented endobronchial biopsy findings in 35 children with long-term wet cough and a temporal or partial response to one or more courses of antibiotics. Although BAL fluid contained a high percentage of neutrophils, no neutrophils were detected in the endobronchial tissue. This finding suggests that the inflammatory patterns in the bronchial wall differ from those at the airway surface. Equally important is the absence of eosinophils and its implication that the pathologic changes underlying PBB differ from those in asthma. These findings extend current knowledge and suggest that PBB belongs to a continuum, along with chronic suppurative lung disease and bronchiectasis [164]. The absence of severe inflammation within the airway wall might explain why patients with PBB usually respond well to appropriate antibiotic treatment and why the disease is reversible. With increasing bacterial infection of the airway wall, structural damage gradually develops.

HATHORN et al. [165] reported six patients with complex air leaks treated with endobronchial balloon occlusion. The intervention was successful in two cases of broncho-pleural fistulae and in one of two cases of intra-pulmonary leak. The effect was only transient in cases of barotrauma and filamin A deficiency. There were no severe adverse effects or complications. The use of endobronchial balloon occlusion has not been described before for these indications in children. Several reports refer to airway balloon occlusion for acute pulmonary haemorrhage in children [166] and combined with endobronchial valves for airway leak in adults [167]. Balloon occlusion might be useful in managing prolonged airway leak in selected cases and may help avoid surgery.

In a multicentre longitudinal analysis of BMI, lung function and sputum microbiology in primary ciliary dyskinesia (PCD), MAGLIONE et al. [168] confirmed that PCD patients receiving centralised care present with a stable BMI and stable spirometry findings over a medium-term follow-up. No significant correlation was found between lung function evolution and $P$. aeruginosa infection, but there was a trend towards a decline in FEV1 after a 2-year follow-up. In their retrospective analysis of growth in 30 children and young adults aged 1.5-24 years with PCD, SvoBodoví et al. [169] documented impaired growth in children with PCD, especially in those at preschool age. As yet, no study has systematically assessed physical growth and development in children with PCD. As reported by the ERS Task Force on PCD, the availability of adequate diagnosis and the quality of care differ significantly between countries [170, 171]. 
Two presentations addressed airway remodelling in children with various chronic respiratory diseases. HonKOva et al. [172] compared histological findings in bronchial mucosa from 31 children with asthma, CF and PCD with those in control subjects. A significant increase in the laminin layer thickness within the basement membrane was found in children with asthma, CF and PCD; no significant differences were found between these diseases. As increased transforming growth factor- $\beta$ activity and thickening of the laminin layer within the basement membrane are also present in other inflammatory conditions associated with bronchial obstruction, they may signal a nonspecific repair process. These data confirm previous findings of remodelling in patients with CF and, to a lesser degree, in PCD patients [173]. LYKOGEORGOU et al. [174] analysed basement membrane thickness in children with asthma and looked for associations with age, atopic status, lung function and other variables. In a group of 15 children (5-11 years of age), they found no association between basement membrane thickness and any of the variables analysed. This lack of association suggests that in asthma, remodelling is present very early during the disease and its development is independent from atopic status or severity of the disease.

Several contributions addressed congenital defects. An interesting case report by LuRÀ et al. [175], describing a neonate with a congenital defect of the epiglottis, documented that even without an epiglottis a child can be fed aspiration-free. Others have already reported that absence of the epiglottis could be compensated for by other mechanisms [176]. The epiglottis may play a role in maintaining upper airway stability and its absence may contribute to OSA.

\section{References}

Midulla F, Lombardi E, Lødrup Carlsen KC, et al. Paediatrics in Vienna. Eur Respir J 2013; 42: 1092-1104. Alblooshi AS, Simpson SJ, Stick SM, et al. The safety and feasibility of the inhaled mannitol challenge test in young children. Eur Respir J 2013; 42: 1420-1423.

3 Alblooshi A, Simpson S, Banton G, et al. The agreement between inhaled mannitol airway challenge and exercise challenge in young children. Eur Respir J 2013; 42: Suppl. 57, 1060s.

Gauld L, Keeling L, Sly P, et al. Value of FOT in young children with SMA. Eur Respir J 2013; 42: Suppl. 57, 227s. Radics B, Gyurkovits Z, Szabo H, et al. Changes in respiratory impedance during deep inspiration in healthy newborns. Eur Respir J 2013; 42: Suppl. 57, 304s-305s.

6 Stick S, Tiddens $\mathrm{H}$, Aurora P, et al. Early intervention studies in infants and preschool children with cystic fibrosis: are we ready? Eur Respir J 2013; 42: 527-538.

7 Robinson PD, Latzin P, Verbanck S, et al. Consensus statement for inert gas washout measurement using multipleand single-breath tests. Eur Respir J 2013; 41: 507-522.

8 Schmidt A, Yammine S, Proietti E, et al. Validation of multiple-breath washout equipment for infants and preschool children. Eur Respir J 2013; 42: Suppl. 57, 990s.

9 Stanojevic S, Jensen R, Subarrao P, et al. Increased within-test variability may bias estimates of the LCI. Eur Respir J 2013; 42: Suppl. 57, 917s.

10 Hatziagorou E, Avramidou V, Kirvasillis F, et al. Ventilation inhomogeneity in children with severe asthma and normal spirometry indicates residual airways disease. Eur Respir J 2013; 42: Suppl. 57, 227s.

11 Fuchs S, Griese M, Staab D, et al. Multiple breath washout for monitoring alpha-1-antitrypsin deficiency related lung disease. Eur Respir J 2013; 42: Suppl. 57, 306s.

12 Yammine S, Singer F, Schmidt A, et al. Ventilation inhomogeneity in preterm children at school age. Eur Respir J 2013; 42: Suppl. 57, 989s.

13 Gauld L, Keeling L, Sly P, et al. Predicting height from ulna length in 2-6 year olds. Eur Respir J 2013; 42: Suppl. 57, 267s.

14 Gauld LM, Kappers J, Carlin JB, et al. Height prediction from ulna length. Dev Med Child Neurol 2004: 46; 475-480.

15 Hüls A, Krämer U, Gappa M, et al. New paediatric spirometry reference values from the LUNOKID study: comparison to Zapletal's and Quanjer's data. Eur Respir J 2013; 42: Suppl. 57, 990s.

16 Quanjer PH, Stanojevic S, Cole TJ, et al. Multi-ethnic reference values for spirometry for the 3-95-yr age range: the global lung function 2012 equations. Eur Respir J 2012; 40: 1324-1343.

17 Zapletal A, Samánek N, Paul T, et al. Lung function in children and adolescents: methods, reference values. Basel, Karger, 1987.

18 Innocenti D, Masi E, Masolini M, et al. Reference values for the 6 minute walk test in healthy Italian children aged 6-11 years. Eur Respir J 2013; 42: Suppl. 57, 989s.

19 Menou A, Babeanu D, Verstraete M, et al. Reference values for offline exhaled and nasal nitric oxide in healthy children. Eur Respir J 2013; 42: Suppl. 57, 917s.

20 Van Holsbeke C, Vos W, Van Hoorenbeeck K, et al. Functional respiratory imaging as a tool to assess upper airway patency in children with OSA. Eur Respir J 2013; 42: Suppl. 57, 306s.

21 Khirani S, Pautrat J, Boulé M, et al. Carbon dioxide monitoring during polygraphy in children with sleep disordered breathing: is it necessary? Eur Respir J 2013; 42: Suppl. 57, 991 s.

22 Alonso-Alvarez ML, Teran-Santos J, Cordero-Guevara JA, et al. Reliability of home respiratory polygraphy monitoring for diagnosis of sleep apnea/hypopnea syndrome (SAHS) in children. Eur Respir J 2013; 42: Suppl. 57, 991s-992s.

23 Namazy JA, Murphy VE, Powell H, et al. Effects of asthma severity, exacerbations and oral corticosteroids on perinatal outcomes. Eur Respir J 2013; 41: 1082-1090.

24 Barker DJP, Godfrey KM, Fall C, et al. Relation of birth weight and childhood respiratory infection to adult lung function and death from chronic obstructive airways disease. BMJ 1991; 303: 671-675.

25 Hallberg J, Thunqvist P, Schultz E, et al. Early-onset transient asthma and impaired lung function in adolescence preliminary data from the BAMSE cohort. Eur Respir J 2013; 42: Suppl. 57, 630s. 
atopic disease phenotypes. Eur Respir J 2013; 42: Suppl. 57, 630s-631s. asthma controller therapy: a 7-year follow-up. Eur Respir J 2013; 42: Suppl. 57, 630 Eur Respir J 2013; 41: 183-188.

29 Gedik AH, Cakir E, Ozkaya E, et al. Does early diagnosis and treatment of the childhood asthma reduce excessive antibiotics usage? Eur Respir J 2013; 42: Suppl. 57, 241s.

30 Stenberg Hammar K, Hedlin G, Konradsen JR, et al. Relevance of respiratory infections in preschool wheeze - a hospital based study. Eur Respir J 2013; 42: Suppl. 57, 631s.

31 Klok T, Kaptein A, Duiverman E, et al. The remarkable role of adherence to inhaled corticosteroids in achieving asthma control in young children with asthma. Eur Respir J 2013; 42: Suppl. 57, 240s.

32 Klok T, Kaptein AA, Duiverman EJ, et al. It's the adherence, stupid (that determines asthma control in preschool children)! Eur Respir J 2014; 43: 783-791.

33 Klok T, Kaptein A, Duiverman E, et al. Once-daily inhaled corticosteroids in children with asthma: not a simple solution for non-adherence. Eur Respir J 2013; 42: Suppl. 57, 919s.

34 Hedlin G, Konradsen A, Bush A. An update on paediatric asthma. Eur Respir Rev 2012; 21: 175-185.

35 Ilyenkova N, Tereshchenko S, Alekseeva O, et al. Uncontrolled asthma in children: The role $\mathrm{M}$. pneumoniae and Cl. Pneumonia. Eur Respir J 2013; 42: Suppl. 57, 237s.

36 Kreggemijer W, de Groot E, Brand PLP. Causes of problematic asthma in children: retrospective cohort study. Eur Respir J 2013; 42: Suppl. 57, 235s.

37 Wahab AA, Maarafiya M, Soliman A, et al. Serum leptin and adiponectin in obese and non-obese asthmatic school children: relation to asthma control. Eur Respir J 2013; 42: Suppl. 57, 234s.

38 Voorend-van Bergen S, Brackel H, Caudri D, et al. Assessment of asthma control by children and parents. Eur Respir J 2013; 41: 233-234.

39 Voorend-van Bergen S, Vaessen-Verberne A, Landstra A, et al. FeNO and web-based monitoring in paediatric asthma management: the BATMAN study. Eur Respir J 2013; 42: Suppl. 57, 629s.

40 van Sprang N, Delgado-Eckert E, Häcki C, et al. A new observer independent method to assess therapy response in children with severe asthma based on daily lung function. Eur Respir J 2013; 42: Suppl. 57, 237 s.

41 Al-Biltagi M, Bediwy AS, Deraz S, et al. Esomeprazole versus esomeprazole and domperidone in treatment of gastroesophageal reflux in children with difficult-to-treat asthma. Eur Respir J 2013; 42: Suppl. 57, 237s.

42 Namazova-Baranova L, Vishneva E, Alekseeva A, et al. Long-term using of omalizumab in children with atopic severe persistent non-controlled asthma. Eur Respir J 2013; 42: Suppl. 57, 236s.

43 Kopp M, Watz H, Lerche K. Effects of Xolair ${ }_{\circledR}$ in children: the X-HALE study. Eur Respir J 2013; 42: Suppl. 57, 236s.

44 Peña JA, de Borja Osona F, Gil JA, et al. Pre-flight hypoxic test in hospitalized children with acute asthma exacerbation. How long should they delay the travel? Eur Respir J 2013; 42: Suppl. 57, 236s.

45 Gustafsson PM, Aurora P, Lindblad A. Evaluation of ventilation maldistribution as an early indicator of lung disease in children with cystic fibrosis. Eur Respir J 2003; 22: 972-979.

46 Lum S, Stocks J, Stanojevic S, et al. Age and height dependence of lung clearance index and functional residual capacity. Eur Respir J 2013; 41: 1371-1377.

47 Kieninger E, Yammine S, Proietti E, et al. Normal lung function in infants with cystic fibrosis shortly after birth. Eur Respir J 2013; 42: Suppl. 57, 1071s.

48 Stahl M, Joachim C, Blessing K, et al. Multiple breath washout is feasible and detects abnormal lung function in infants and young children with cystic fibrosis in the clinical setting. Eur Respir J 2013; 42: Suppl. 57, 419s-420s.

49 Thia LP, Hoo A, Brennan L, et al. Stable lung function is maintained over 2 years in newborn screened (NBS) CF infants. Eur Respir J 2013; 42: Suppl. 57, 1072s.

50 Ramsey K, Ranganathan S, Skoric B, et al. Structural lung disease, pulmonary infection and inflammation in infancy is associated with reduced spirometry at school-age in children with cystic fibrosis (CF). Eur Respir J 2013; 42: Suppl. 57, 1072s.

51 Sly PD, Gangell CL, Chen L, et al. Risk factors for bronchiectasis in children with cystic fibrosis. N Engl J Med 2013; 368: 1963-1970.

52 Aurora P, Stanojevic S, Wade A, et al. Lung clearance index at 4 years predicts subsequent lung function in children with cystic fibrosis. Am J Respir Crit Care Med 2011; 183: 752-758.

53 Owens CM, Aurora P, Stanojevic S, et al. Lung clearance index and HRCT are complementary markers of lung abnormalities in young children with CF. Thorax 2011; 66: 481-488.

54 Subbarao P, Stanojevic S, Brown M, et al. Lung clearance index as an outcome measure for clinical trials in young children with cystic fibrosis. A pilot study using inhaled hypertonic saline. Am J Respir Crit Care Med 2013; 188: 456-460.

55 Sheikh S, Flucke R, Ryan-Wanger N, et al. Changes in stop ventilation HRCT of chest following antibiotics in infants with pulmonary exacerbation of cystic fibrosis. Eur Respir J 2013; 42: Suppl. 57, 1072s.

56 Sheikh S, Flucke R, Ryan-Wanger N, et al. Changes in pulmonary function tests following antibiotics in infants with pulmonary exacerbation of cystic fibrosis. Eur Respir J 2013; 42: Suppl. 57, 1073s.

57 Welsh L, Tomai M, Tran H, et al. Lung clearance index during pulmonary exacerbation in school-age children with cystic fibrosis. Eur Respir J 2013; 42: Suppl. 57, 743s.

58 Al-Khathlan N, Gaillard E, Beardsmore C. Ventilation inhomogeneity (VI) and spirometry in response to intravenous antibiotics (IVab) in cystic fibrosis (CF). Eur Respir J 2013; 42: Suppl. 57, 743s.

59 Kuo W, Bos A, Stick S, et al. Prevalence of bronchiectasis on chest computed tomography in young patients with cystic fibrosis using two different image analysis strategies. Eur Respir J 2013; 42: Suppl. 57, 1073s.

60 Bortoluzzi CF, Volpi S, D'Orazio C, et al. Significant lung damage revealed at early chest computed tomography is related to subsequent pseudomonas (PsA) colonization in children with cystic fibrosis. Eur Respir J 2013; 42: Suppl. 57, 742s.

61 Houltz B, Gilljam M, Rosberg M, et al. Sensitivity of N2 single breath washout (SBW) compared multiple breath washout (MBW) in adults with cystic fibrosis (CF). Eur Respir J 2013; 42: Suppl. 57, 742s. 
62 Lindblad A, Rosberg M, Houltz B, et al. Prospective follow up over 1 year with N2 multiple breath washout (MBW) in children with cystic fibrosis. Eur Respir J 2013; 42: Suppl. 57, 744s.

63 Warnock L, Gates A, van der Schans CP. Chest physiotherapy compared to no chest physiotherapy for cystic fibrosis. Cochrane Database Syst Rev 2013; 9: CD001401.

64 Wettstein M, Riedel T. Effect of different physiotherapy devices on ventilation distribution in adults with cystic fibrosis. Eur Respir J 2013; 42: Suppl. 57, 741s.

65 Pfleger A, Steinbacher M, Weinhandl E, et al. Short-term effects of physiotherapy on ventilation inhomogeneity in cystic fibrosis patients with moderate to severe lung disease. Eur Respir J 2013; 42: Suppl. 57, 741s.

66 Kriemler S, Kieser S, Junge S, et al. Effect of supervised training on FEV1 in cystic fibrosis: a randomised controlled trial. J Cyst Fibros 2013; 12: 714-720.

67 Schneiderman JE, Wilkes DL, Atenafu EG, et al. Longitudinal relationship between physical activity and lung health in patients with cystic fibrosis. Eur Respir J 2014; 43: 817-823.

68 Karapanagiotis S, Brivio A, Gambazza S, et al. Exercise and sport habits in children and adolescents with cystic fibrosis. Eur Respir J 2013; 42: Suppl. 57, 741s-742s.

69 Savi D, Onorati P, Di Paolo M, et al. Intensity of daily activity may affect exercise capacity and peripheral muscle function in adults with cystic fibrosis. Eur Respir J 2013; 42: Suppl. 57, 742s.

70 Laskine M, Tardif V, Ptaszynski S, et al. Regular exercise improves airway inflammation in cystic fibrosis patients. Eur Respir J 2013; 42: Suppl. 57, 741s.

71 Tunney MM, Field TR, Moriarty TF, et al. Detection of anaerobic bacteria in high numbers in sputum from patients with cystic fibrosis. Am J Respir Crit Care Med 2008; 177: 995-1001.

72 Zhao J, Schloss PD, Kalikin LM, et al. Decade-long bacterial community dynamics in cystic fibrosis airways. Proc Natl Acad Sci USA 2012; 109: 5809-5814.

73 Bertelsen A, Ennis M, Elborn S. Anaerobic bacteria and host defence in cystic fibrosis. Eur Respir J 2013; 42: Suppl. 57,422 s.

74 Ciofu O, Hansen CR, Høiby N. Respiratory bacterial infections in cystic fibrosis. Curr Opin Pulm Med 2013; 19: 251-258.

75 Kumar A, Etherington C, Peckham DG. Incidence and prevalence of non tuberculous mycobacteria (NTM) in adult CF population: a large adult CF centre experience. Eur Respir J 2013; 42: Suppl. 57, $246 s$.

76 Godbert B, Briault A. Cystic fibrosis: Achromobacter xylosoxidans colonized patients have more severe respiratory disease. Eur Respir J 2013; 42: Suppl. 57, $246 s$.

77 Robson J, Etherington C, Peckham D. Retrospective cohort study of adult cystic fibrosis patients colonised with Achromobacter xylosoxidans. Eur Respir J 2013; 42: Suppl. 57, $246 s$.

78 Fustik S, Jakovska T, Spirevska L. Eradication regime of methicillin resistant Staphylococcus aureus lung infection in cystic fibrosis. Eur Respir J 2013; 42: Suppl. 57, 246 s.

79 Vanderhelst E, De Wachter E, Willekens J, et al. Successful eradication of methicillin-resistant Staphylococcus aureus in chronically colonized cystic fibrosis patients. Eur Respir J 2013; 42: Suppl. 57, 251 .

80 Amaddeo A, Bramuzzo M, Saletta S, et al. Steroid sparing effect of anti-IgE antibody in allergic bronchopulmonary aspergillosis (ABPA) complicating cystic fibrosis. Eur Respir J 2013; 42: Suppl. 57, 251 s.

81 Kieninger E, Singer F, Tapparel C, et al. High rhinovirus burden in lower airways of children with cystic fibrosis. Chest 2013; 143: 782-790.

82 Flight WG, Bright-Thomas RJ, Tilston $\mathrm{P}$, et al. Incidence and clinical impact of respiratory viruses in adults with cystic fibrosis. Thorax 2014; 69: 247-253.

83 Shah A, Connolly M, Clasper L, et al. Frequency and pathogenicity of rhinovirus associated pulmonary exacerbations in patients with cystic fibrosis. Eur Respir J 2013; 42: Suppl. 57, 742 s.

84 Jarad N, Sequeiros I, Patel P, et al. Fatigue in cystic fibrosis: a novel prospective study investigating subjective and objective factors associated with fatigue. Eur Respir J 2013; 42: Suppl. 57, 247s.

85 Di Cicco M, Luca N, Pignataro L, et al. Sinonasal mucoceles in cystic fibrosis. Eur Respir J 2013; 42: Suppl. 57, $248 \mathrm{~s}$.

86 Raju SV, Jackson P, Courville C, et al. Cigarette smoke induces systemic defects in cystic fibrosis transmembrane conductance regulator (CFTR) ion transport. Eur Respir J 2013; 42: Suppl. 57, 420s.

87 Stokes KL, Currier MG, Sakamoto K, et al. The respiratory syncytial virus fusion protein and neutrophils mediate the airway mucin response to pathogenic respiratory syncytial virus infection. J Virol 2013; 87: 10070-10082.

88 Saint G, Flanagan B, McNamara P, et al. The role of neutrophils in viral clearance during respiratory syncytial virus (RSV) disease. Eur Respir J 2013; 42: Suppl. 57, 48s.

89 Jeyatheswaran J, Apperley L, McNamara P, et al. A549 cell expression of ubiquitin E3 ligase RNF168 is decreased following RSV infection but increased by interferon beta treatment. Eur Respir J 2013; 42: Suppl. 57, 253s.

90 Drysdale S, Prendergast M, Alcazar-Paris M, et al. Genetic predisposition to RSV infection and associated respiratory morbidity in preterm infants. Eur Respir J 2013; 42: Suppl. 57, 252 s.

91 Drysdale SB, Alcazar-Paris M, Wilson T, et al. Rhinovirus infection and healthcare utilisation in prematurely born infants. Eur Respir J 2013; 42: 1029-1036.

92 Mack I, Singh P, Cangiano G, et al. Clinical impact of rhinovirus infections in infancy. Eur Respir J 2013; 42: Suppl. 57, 253s.

93 Kanik ET, Yilmaz O, Turkeli A, et al. Clinical characteristics and prognosis of respiratory viral agents in hospitalized children during one year period. Eur Respir J 2013; 42: Suppl. 57, 253 s.

94 Yoshida LM, Suzuki M, Nguyen HA, et al. Respiratory syncytial virus: co-infection and paediatric lower respiratory tract infections. Eur Respir J 2013; 42: 461-469.

95 Strachan RE, Snelling TL, Jaffé A. Increased paediatric hospitalizations for empyema in Australia after introduction of the 7-valent pneumococcal conjugate vaccine. Bull World Health Organ 2013; 91: 167-173.

96 Escobar K, Castellanos V, Mejia M. Empyema in children, clinical characteristics and therapeutic trends in Quetzaltenango, Guatemala. Eur Respir J 2013; 42: Suppl. 57, 254s.

97 Proesmans M, Gijsen B, van de Wijdeven P, et al. Does standardized medical treatment for parapneumonic empyema (PE) in children reduce the need for surgical intervention. Eur Respir J 2013; 42: Suppl. 57, 47s-48s.

98 Sawicki GS, Lu FL, Valim C, et al. Necrotising pneumonia is an increasingly detected complication of pneumonia in children. Eur Respir J 2008; 31: 1285-1291. 
99 Blanchon S, Anastaze Stelle K, Mornand A, et al. Should empyema be managed differently in case of necrotizing pneumonia? Eur Respir J 2013; 42: Suppl. 57, 49s.

100 Grigg J, Walters H, Sohal SS, et al. Cigarette smoke and platelet-activating factor receptor dependent adhesion of Streptococcus pneumoniae to lower airway cells. Thorax 2012; 67: 908-913.

101 Grigg J. The platelet activating factor receptor: a new anti-infective target in respiratory disease? Thorax 2012; 67: 840-841.

102 Yamaya M, Nishimura H, Hatachi Y, et al. Levofloxacin inhibits rhinovirus infection in primary cultures of human tracheal epithelial cells. Antimicrob Agents Chemother 2012; 56: 4052-4061.

103 Galmès J, Li Y, Rajoharison A, et al. Potential implication of new torque teno mini viruses in parapneumonic empyema in children. Eur Respir J 2013; 42: 470-479.

104 Bhatt S, Alison BJ, Wallace EM, et al. Delaying cord clamping until ventilation onset improves cardiovascular function at birth in preterm lambs. J Physiol 2013; 591: 2113-2126.

105 Milner A, Murthy V, Milner A, et al. Evaluation of respiratory function monitoring during the resuscitation of prematurely born infants. Eur Respir J 2013; 42: Suppl. 57, 409s.

106 Bhat P, Murthy V, Fox G, et al. The effects of increasing inflation pressures in the resuscitation of prematurely born infants. Eur Respir J 2013; 42: Suppl. 57, 409s.

107 Kamlin CO, Schilleman K, Dawson JA, et al. Mask versus nasal tube for stabilization of preterm infants at birth: a randomized controlled trial. Pediatrics 2013; 132: e381-e388.

108 McCarthy LK, Twomey AR, Molloy EJ, et al. A randomized trial of nasal prong or face mask for respiratory support for preterm newborns. Pediatrics 2013; 132: e389-e395.

109 Dargaville PA, Aiyappan A, De Paoli AG, et al. Minimally-invasive surfactant therapy in preterm infants on continuous positive airway pressure. Arch Dis Child Fetal Neonatal Ed 2013; 98: F122-F126.

110 Kanmaz HG, Erdeve O, Canpolat FE, et al. Surfactant administration via thin catheter during spontaneous breathing: randomized controlled trial. Pediatrics 2013; 131: e502-e509.

111 Fischer H, Bührer C. Avoiding mechanical ventilation to prevent bronchopulmonary dysplasia: a meta-analysis. Eur Respir J 2013; 42: Suppl. 57, 407s-408s.

112 Mehler K, Grimme J, Abele J, et al. Outcome of extremely low gestational age newborns after introduction of a revised protocol to assist preterm infants in their transition to extrauterine life. Acta Paediatr 2012; 101: 1232-1239.

113 Sweet DG, Carnielli V, Greisen G, et al. European consensus guidelines on the management of neonatal respiratory distress syndrome in preterm infants - 2013 update. Neonatology 2013; 103: 353-368.

114 The BOOST II United Kingdom, Australia, and New Zealand Collaborative Groups. Oxygen saturation and outcomes in preterm infants. N Engl J Med 2013; 368: 2094-2104.

115 Polycarpou E, Zachaki S, Polycarpou N, et al. L-arginine for chronic lung disease (CLD) in preterm neonates. Eur Respir J 2013; 42: Suppl. 57, 409s.

116 Zivanovic S, Lo J, Alcazar Paris M, et al. Longitudinal study of lung function in very prematurely born infants. Eur Respir J 2013; 42: Suppl. 57, 410s.

117 Caskey S, Gillespie S, Clarke J, et al. Structural lung disease in adult survivors of bronchopulmonary dysplasia. Eur Respir J 2013; 42: Suppl. 57, 410s.

118 Kotecha SJ, Edwards MO, Watkins WJ, et al. Effect of preterm birth on later FEV1: a systematic review and metaanalysis. Thorax 2013; 68: 760-766.

119 Da Dalt L, Bressan S, Martinolli F, et al. Treatment of bronchiolitis: state of the art. Early Hum Dev 2013; 89: Suppl. 1, S31-S36.

120 Krivec U, Praprotnik M, Aldeco M. High flow nasal cannula therapy improves clinical and gas exchange parameters in children with acute bronchiolitis. Eur Respir J 2013; 42: Suppl. 57, 408s.

121 Milési C, Baleine J, Matecki S, et al. Is treatment with a high flow nasal cannula effective in acute viral bronchiolitis? A physiologic study. Intensive Care Med 2013; 39: 1088-1094.

122 Manley BJ, Owen LS, Doyle LW, et al. High-flow nasal cannulae in very preterm infants after extubation. $N$ Engl J Med 2013; 369: 1425-1433.

123 Duijts L. Fetal and infant origins of asthma. Eur J Epidemiol 2012; 27: 5-14

124 Zugna D, Galassi C, Annesi-Maesano I, et al. Maternal complications and conditions in pregnancy and wheezing in early childhood: a combined analysis of 14 European birth cohorts. Eur Respir J 2013; 42: Suppl. 57, 341s.

125 Leermakers ET, Sonnenschein-van der Voort AM, Gaillard R, et al. Maternal weight, gestational weight gain and preschool wheezing. The generation R study. Eur Respir J 2013; 42: 1234-1243.

126 Sonnenschein-van der Voort AMM, Arends LR, de Jongste JC, et al. Early growth and the risk of childhood asthma: a meta-analysis of 147,000 European children. Eur Respir J 2013; 42: Suppl. 57, 715s.

127 Sonnenschein-van der Voort AMM, Howe LD, Granell R, et al. Influence of childhood growth on asthma and lung functioning in adolescence. Eur Respir J 2013; 42: Suppl. 57, 340s-341s.

128 de Korte-de Boer D, Mommers M, Thijs C, et al. Association of early life growth rates with childhood wheezing and overweight. Eur Respir J 2013; 42: Suppl. 57, 340s.

129 Pike K, Inskip H, Crozier S, et al. Does childhood obesity influence asthma, or wheeze phenotype at age 6 years? Eur Respir J 2013; 42: Suppl. 57, 340s.

130 van der Gugten AC, Koopman N, Evelein AM, et al. Rapid early weight gain is associated with wheeze and reduced lung function in childhood. Eur Respir J 2012; 39: 403-410.

131 Granell R, Henderson J, Evans D, et al. Associations of BMI, fat mass and lean mass with childhood asthma: Mendelian randomization study. Eur Respir J 2013; 42: Suppl. 57, 714s.

132 Speliotes EK, Willer CJ, Berndt SI, et al. Association analyses of 249,796 individuals reveal eighteen new loci associated with body mass index. Nat Genet 2010; 42: 937-948.

133 Schultz ES, Hallberg J, Bellander T, et al. Early life exposure to traffic-related air pollution and lung function in adolescence. Eur Respir J 2013; 42: Suppl. 57, 715s.

134 Schultz ES, Gruzieva O, Bellander T, et al. Traffic-related air pollution and lung function in children at 8 years of age: a birth cohort study. Am J Respir Crit Care Med 2012; 186: 1286-1291.

135 Hoek G, Pattenden S, Willers S, et al. PM10, and children's respiratory symptoms and lung function in the PATY study. Eur Respir J 2012; 40: 538-547. 
Garcia-Marcos P, Pacheco-Gonzalez R, Sanchez-Solis M, et al. Parental history of atopy modifies the effect of breast feeding on recurrent wheeze in infants. Eur Respir J 2013; 42: Suppl. 57, 342s.

137 Dogaru C, Pescatore A, Baeuml J, et al. Breastfeeding and rhinoconjunctivitis: a cohort study. Eur Respir J 2013; 42: Suppl. 57, 342s.

138 Goksör E, Alm B, Petterson R, et al. Early fish introduction and neonatal antibiotics affect the risk of asthma into school age. Eur Respir J 2013; 42: Suppl. 57, 341s.

139 Kremmyda LS, Vlachava M, Noakes PS, et al. Atopy risk in infants and children in relation to early exposure to fish, oily fish, or long-chain omega-3 fatty acids: a systematic review. Clin Rev Allergy Immunol 2011; 41: 36-66.

140 Roduit C, Frei R, Depner M, et al. An increased diversity of food introduced in the first year of life as a protective factor for allergic diseases. Eur Respir J 2013; 42: Suppl. 57, 716s.

141 Rusconi F, Spycher BD, Kuehni CE. Epidemiology and phenotypes of bronchial asthma and wheezing disorders. In: Eber E, Midulla F, eds. ERS Handbook of Paediatric Respiratory Medicine. 1st Edn. Sheffield, European Respiratory Society, 2013; pp. 293-297.

142 Turner S, Mullane D, Cox D, et al. Associations with a change in tracking of lung function. Eur Respir J 2013; 42: Suppl. 57, 338s.

143 Warm K, Bjerg A, Hedman L, et al. High incidence and persistence of allergic sensitization from age 7 to 19 years. Eur Respir J 2013; 42: Suppl. 57, 339s.

144 Marshall L, Beardsmore C, Montero W, et al. Increased airway inflammation in asymptomatic older teenagers with previous well characterised childhood wheeze. Eur Respir J 2013; 42: Suppl. 57, 339s.

145 Pinart M, Benet M, Annesi-Maesano I, et al. Comorbidity and persistence of allergy-related phenotypes in children in the longitudinal MeDALL study. Eur Respir J 2013; 42: Suppl. 57, 716s.

146 Damgaard AL, Hansen BM, Mathiasen R, et al. Prematurity and use of asthma medication from childhood to young adulthood. Eur Respir J 2013; 42: Suppl. 57, 258s.

147 Weil-Olivier C, van der Linden M, de Schutter I, et al. Prevention of pneumococcal diseases in the post-seven valent vaccine era: a European perspective. BMC Infect Dis 2012; 12: 207.

148 Pinto L, Veras T, Scotta M, et al. Impact of introducing the 10-valent pneumococcal conjugate vaccine on childhood hospitalizations for bacterial pneumonia in Brazil. Eur Respir J 2013; 42: Suppl. 57, 924s.

149 Lieberoth S, Gade E, Kyvik KO, et al. Early menarche is associated with increased risk of asthma: Prospective population-study of twins. Eur Respir J 2013; 42: Suppl. 57, 716s.

150 Yonas MA, Lange NE, Celedón JC. Psychosocial stress and asthma morbidity. Curr Opin Allergy Clin Immuno 2012; 12: 202-210.

151 Havland I, Lundholm C, Lichtenstein P, et al. Maternal anxiety and adolescent asthma: children of twin design suggest familial effects. Eur Respir J 2013; 42: Suppl. 57, 338s.

152 Schramm D, Ling K, Schuster A. Management of foreign body aspiration - a nation-wide survey. Eur Respir J 2013; 42: Suppl. 57, 1061s

153 Barbato A, Magarotto M, Crivellaro M, et al. Use of the paediatric bronchoscope, flexible and rigid, in 51 European centres. Eur Respir J 1997; 10: 1761-1766.

154 Swanson KL, Prakash UB, Midthun DE, et al. Flexible bronchoscopic management of airway foreign bodies in children. Chest 2002; 121: 1695-1700.

155 Tang LF, Xu YC, Wang YS, et al. Airway foreign body removal by flexible bronchoscopy: experience with 1027 children during 2000-2008. World J Pediatr 2009; 5: 191-195.

156 Aslan AT, Topal E, Eyuboglu T, et al. Which bronchoscopy procedure should be chosen for foreign body aspiration in children: Rigid, flexible or combined? Eur Respir J 2013; 42: Suppl. 57, 262s.

157 Kut A, Cakir E, Gökdemir Y, et al. Intrinsic endobronchial obstructions in children from Turkey: Evaluation of 2,555 flexible bronchoscopic procedures. Eur Respir J 2013; 42: Suppl. 57, 1061s.

158 Cakir E, Kut A, Ozkaya E, et al. Bronchoscopic evaluation of childhood pulmonary tuberculosis: Risk factors of airway involvement and contribution of BAL in the bacteriological diagnosis. Eur Respir J 2013; 42: Suppl. 57, 1061s-1062s.

159 Cakir E, Uyan ZS, Oktem S, et al. Flexible bronchoscopy for diagnosis and follow up of childhood endobronchial tuberculosis. Pediatr Infect Dis J 2008; 27: 783-787.

160 Reiter J, Colin AA, Kontopoulos EV, et al. Fetal bronchoscopy for treatment of congenital pulmonary anomalies. Eur Respir J 2013; 42: Suppl. 57, 1062s.

161 Quintero RA, Kontopoulos E, Reiter J, et al. Fetal bronchoscopy: its successful use in a case of extralobar pulmonary sequestration. J Matern Fetal Neonatal Med 2012; 25: 2354-2358.

162 Martínez JM, Prat J, Gómez O, et al. Decompression through tracheobronchial endoscopy of bronchial atresia presenting as massive pulmonary tumor: a new indication for fetoscopic surgery. Fetal Diagn Ther 2013; 33: 69-74.

163 Douros K, Kitsanta P, Mermiri D, et al. Endobronchial biopsies in children with protracted bacterial bronchitis. Eur Respir J 2013; 42: Suppl. 57, 1062s.

164 Chang AB, Redding GJ, Everard ML. Chronic wet cough: Protracted bronchitis, chronic suppurative lung disease and bronchiectasis. Pediatr Pulmonol 2008; 43: 519-531.

165 Hathorn C, Armitage N, Wensley D, et al. Bronchial balloon occlusion in children with complex pulmonary air leaks. Eur Respir J 2013; 42: Suppl. 57, 1062s.

166 Sidman JD, Wheeler WB, Cabalka AK, et al. Management of acute pulmonary hemorrhage in children. Laryngoscope 2001; 111: 33-35.

167 Kovitz KL, French KD. Endobronchial valve placement and balloon occlusion for persistent air leak: procedure overview and new current procedural terminology codes for 2013. Chest 2013; 144: 661-665.

168 Maglione M, Bush A, Nielsen K, et al. Multicentre longitudinal analysis of body mass index, lung function and sputum microbiology in primary ciliary dyskinesia. Eur Respir J 2013; 42: Suppl. 57, 1062s.

169 Svobodová T, Djakow J, Zemková D, et al. Impaired childhood growth velocity in patients with primary ciliary dyskinesia. Eur Respir J 2013; 42: Suppl. 57, 260s.

170 Kuehni CE, Frischer T, Strippoli MP, et al. ERS Task Force on Primary Ciliary Dyskinesia in Children. Factors influencing age at diagnosis of primary ciliary dyskinesia in European children. Eur Respir J 2010; 36: 1248-1258

171 Strippoli M-PF, Frischer T, Barbato A, et al. Management of primary ciliary dyskinesia in European children: recommendations and clinical practice. Eur Respir J 2012; 39: 1482-1491. 
172 Honkova L, Berankova K, Uhlik J, et al. Increased laminin deposition and expression of TGF- $\beta$ in bronchial biopsies of children with chronic obstructive respiratory diseases. Eur Respir J 2013; 42: Suppl. 57, 265 s.

173 Hilliard TN, Regamey N, Shute JK, et al. Airway remodelling in children with cystic fibrosis. Thorax 2007; 62: $1074-1080$.

174 Lykogeorgou M, Panaghiotopoulou-Gartagani P, Choulakis M, et al. Airway basement membrane thickness in children with asthma. Eur Respir J 2013; 42: Suppl. 57, 265 s.

175 Lurà MP, Trachsel D, Hammer J. Can infants without epiglottis learn to swallow? Eur Respir J 2013; 42: Suppl. 57, 263s.

176 Bonilla JA, Pizzuto MP, Brodsky LS. Aplasia of the epiglottis: a rare congenital anomaly. Ear Nose Throat J 1998; 77 : 51-55. 